\title{
Typical Pressure Drop Calculation Formula for the Applicability of the Pressure Drop of Gelled Crude Oil Hydraulic Suspension Transportation
}

\author{
Fuzhang Li \\ Northeast Petroleum University; \\ Daqing Oilfield co., LTD. 9 Production Plant \\ Daqing, China \\ e-mail: a6503441@163.com \\ Yang Liu \\ Northeast Petroleum University \\ Daqing, China \\ e-mail: a6503441@163.com \\ Jingfen Li \\ Daqing Vocational College \\ Daqing, China \\ e-mail: $\underline{\text { 66503441@,163.com }}$
}

\author{
Rongru He \\ Northeast Petroleum University \\ Daqing, China \\ e-mail: a6503441@163.com
}

\author{
Xiaoyan Liu \\ Northeast Petroleum University \\ Daqing, China \\ e-mail: $\underline{\text { a6503441@,163.com }}$
}

\begin{abstract}
The pressure drop is the main parameter which influences the safe operation of the gelled crude oil hydraulic suspension transportation system. According to the current specification for design of oil and gas gathering and transferring rules three types of frictional resistance coefficient calculation model (Colebrook formula, Isaev formula and Atlas Schur formula), contrast and analyse the pressure drop values measured in gelled crude oil hydraulic suspension transportation and calculated with the model. The results show that the pressure drop calculated with Colebrook, Isaev and Atlas Schur formulas error exceeding $\mathbf{7 1 \%}$, and they are not suitable for pressure drop calculation of gelled crude oil hydraulic suspension transportation. So new methods for pressure drop calculation should be found .
\end{abstract}

Keywords- multiphase flow; gelled crude oil; experimental study; pressure drop; hydraulic suspension

\section{INTRODUCTION}

Based on the peripheral oil fields of Daqing region with the character dispersion, low capacity, high water cut, and different physical property of crude oil, in order to determine the economic and reasonable way to collect the oil and achieve the goal of no or less heating, many research have been carried out on low temperature hydraulic suspension transportation without heating. In the process of oilfield exploitation, pipeline pressure drop is the main technical basis of operation management in gathering and transferring system [1], and is related to the safe operation of the whole system. Therefore, the accurate calculation of pressure drop in low temperature hydraulic suspended pipeline is of great significance.

Liu Xiaoyan, etc. [1-6] has done a lot of related research on the change of the pressure drop in Daqing crude oil gathering and transferring system. With the data measured in the field the Baker model has been revised, giving the pressure drop calculation method in oil-gaswater horizontal pipeline with supper high-water-cut. Huang Binghua[7] proposed the pressure drop of oil-gaswater must be calculated based on flow pattern, and different flow pattern adopts different formula. This calculation method needs to calculate the mass flow rate of oil-gas-water of each phase and the pressure drop of each phase in the pipeline separately. Chen Jie, etc. [8]carried out experiments on the pressure drop of oil-water two phase flow by using white oil and water. Aiming at all kinds of flow pattern, they analyze the law of oil and water two-phase flow pressure drop and effective viscosity of oil-water mixture, pointing out that the effective viscosity method is only applicable to predict the pressure drop of oil and water dispersion flow.Gong Jing, etc. [9] have studied the law of pressure drop of different flow pattern with three kinds of high viscosity oil and water. Based on the experimental data and theoretical analysis, the experimental relational of the effective viscosity is established. The pressure drop can be estimated with the relational between effective viscosity and mixed flow. Liu Wenhong, etc. [10] adopt Lock - hart - Martinelli correlation method to arrange the experimental data typical flow pattern. Combined with particular cases the 
correlation parameter $\mathrm{C}$ was redefined and the pressure gradient calculation model was proposed based on the typical flow pattern. The pressure drop change law of oil and gas two phase flow in a horizontal pipe were also analyzed and discussed. Hall, etc. [11] carried out the research on the pressure drop laws of oil-gas-water flow. Relevant researchers using Beggs - Brill two-phase flow theory, calculated the mixture viscosity meeting the Malinowsky test data. Under the type of three-phase slug flow pressure drop law study, using the modified Dukler related Hubbard two-phase flow type theoretical calculation, the results are more accurate than Beggs - Brill. Neogi, etc. [12] proposed oil-gas-water stratified flow mechanics model, and when given the apparent phase velocity, fluid properties, and pipe diameter, the model can predict the thickness of oil layer and water layer in the stratified flow. Odozi, etc. [13] found in the three-phase flow experiment, combining Brinkman oil-water viscosity calculation formula with Beggs - Brill calculation formula calculation of three-phase flow pipeline, a satisfied result is obtained. D. p. Chakrabarti [14] established the model based on the minimization of energy and pressure equalization principle.

Predecessors' research on oil and gas multiphase flow pressure drop have made remarkable achievements, but the temperature is above freezing point, and media rarely used crude oil. The temperature below the freezing point of water - gelled crude oil multiphase flow is with nonNewtonian fluid properties, of which rheology is extremely complex and is different from the traditional oil - gas - water multiphase flow. Liu Xiaoyan , etc. [15] used the method of dimensional analysis on gelled crude oil water two-phase flow pressure drop calculation model, but the gelled crude oil - gas - water multiphase flow pressure drop research has not been reported. So this article according to the current spcification for design of oil and gas gathering and transferring regulation of three kinds of frictional resistance coefficient calculation model (Colebrook formula, Isaev formula and Atlas Schur formula), contrast and analyse the gelled crude oil hydraulic suspension transportation pressure drop measured values and the model calculated values, and judge the current specification for design of oil and gas gathering and transferring rules of three types of frictional resistance coefficient calculation model is suitable for gelled crude oil hydraulic suspension transportation or not.

\section{TYPICAL CALCULATION METHODS OF PRESSURE DROP}

\section{A. Baker Model}

Baker model is a conventional calculation model for pressure drop. In the $1950 \mathrm{~s}$, Baker did many researches on experimental data and data of gas-liquid line of production which were obtained by many researchers', and they are based on boundary figure of flow pattern. Then empirical relational for different flow pattern coefficient of gas phase was obtained.

Baker's pressure drop formula was calculated by changing oil-gas-water flow into gas flow, the calculation formula is:

$$
\begin{gathered}
\frac{d p}{d l}=\phi_{g}^{2}\left(\frac{d p}{d l}\right)_{g} \\
\left(\frac{d p}{d l}\right)_{g}=\frac{\lambda_{g} \cdot x^{2} \cdot G^{2}}{d \cdot 2 A^{2} \cdot \rho_{g}} \\
\lambda_{g}=\frac{0.009407}{\sqrt[3]{d}} \\
x=\frac{G_{g}}{G}
\end{gathered}
$$

\section{CI-CO:}

$\phi_{g}^{2}$ - points and the reduction factor of gas phase;

$$
\left(\frac{d p}{d l}\right)_{g} \text { - pressure drop only when the gas flow in }
$$

the pipeline, $\mathrm{Pa}$;

$\lambda_{g}$ - the hydraulic friction coefficient of gas only;

$x$ - quality gas rate;

$G_{g}$ - the mass flow-rate of gas phase in the pipeline, $\mathrm{kg} / \mathrm{s}$;

$G$ - the mass flow-rate of oil-gas-water in the pipeline, $\mathrm{kg} / \mathrm{s}$;

$d$-pipe diameter, $\mathrm{m}$;

$A$-cross-sectional area of the pipeline, $\mathrm{m}^{2}$;

$\rho_{g}$-density of gas, $\mathrm{kg} / \mathrm{m}^{3}$.

Baker did many researches on experimental data and data of gas-liquid line of production which were obtained by many researchers', and they are based on boundary figure of flow pattern.

bubble flow

$$
\phi_{g}^{2}=53.88 X^{1.5}\left(\frac{A}{G_{l}}\right)^{0.2}
$$

air mass flow

$$
\phi_{g}^{2}=79.03 X^{1.31}\left(\frac{A}{G_{l}}\right)^{0.34}
$$

stratified flow

$$
\phi_{g}^{2}=6120 X^{2}\left(\frac{A}{G_{l}}\right)^{1.6}
$$

wave flow

$$
-\frac{d p}{d l}=\lambda_{\text {波 }} \frac{\omega_{s g}^{2} \rho_{g}}{2 d}
$$

In which $\lambda_{\text {波 }}=0.0175\left(\frac{G_{l} \mu_{l}}{G_{g} \mu_{g}}\right)^{0.209}$ 
impact flow

$$
\phi_{g}^{2}=1920 X^{1.63}\left(\frac{A}{G_{l}}\right)
$$

annular flow

$$
\begin{gathered}
\phi_{g}^{2}=(4.8-12.3 d)^{2} X^{2(0.343-0.826 d)} \\
\omega_{s g}=\frac{Q_{g}}{A} \\
X^{2}=\frac{\left(\frac{d p}{d l}\right)_{l}}{\left(\frac{d p}{d l}\right)_{g}}=\frac{\phi_{g}^{2}}{\phi_{l}^{2}} \\
\left(\frac{d p}{d l}\right)_{l}=\frac{\lambda_{l}(1-x)^{2} G^{2}}{2 d A^{2} \rho_{l}} \\
\lambda_{l}=\frac{A_{1}}{\operatorname{Re}^{m}}
\end{gathered}
$$

\section{CI-CO:}

$$
\begin{aligned}
& G_{l} \text { - the mass flow-rate of liquid phase, } \mathrm{kg} / \mathrm{s} ; \\
& \lambda_{\text {波 一 the hydraulic friction coefficient of waves }}
\end{aligned}
$$

flow;

$$
\begin{aligned}
& \omega_{s g} \text { - the gas phase conversion rate, } \mathrm{m} / \mathrm{s} \text {; } \\
& \mu_{g}, \mu_{l} \text { — the dynamic viscosity of gas and liquid }
\end{aligned}
$$
phase in pipeline, $\mathrm{mPa} \cdot \mathrm{s}$;

$\left(\frac{d p}{d l}\right)_{l}$ - pressure drop only when the liquid flow in the pipeline, $\mathrm{Pa}$;

$\lambda_{l}$ - the hydraulic friction coefficient of liquid only;

$\rho_{l}$-density of gas, $\mathrm{kg} / \mathrm{m} 3$;

$A_{1}$ - the coefficient, laminar flow $A_{1}=64$; the hydraulic smooth area $A_{1}=0.316$; mixed friction ${ }^{\text {area }} A_{1}=10^{\left(0.127 \lg \frac{e}{d}-0.627\right)}$

$\mathrm{m}$-the coefficient, laminar flow $\mathrm{m}=1$; the hydraulic smooth area $\mathrm{m}=0.25$; mixed friction area $\mathrm{m}=0.123$;

Re-Reynolds number.

When calculating the pressure drop of oil-gas-water flow, Baker model is more widely used, but it has a big deficiency, and that's most of the his experimental data were collected from $152.4 \sim 254.0 \mathrm{~mm}$ diameter of oil-gas transmission pipeline, so the formula given is just suitable the oil-gas pipeline whose diameter is above $152.4 \mathrm{~mm}$. For the test of small diameter, Baker model for gelled crude oil hydraulic suspension transportation in calculating pressure drop has some limitations.

\section{B. The friction drag coefficient calculation model}

In the process of oil-gas-water losing transportation, if calculating the pressure loss, determining the head loss is most important, and the magnitude of the head loss has a direct relationship with friction coefficient. Therefore, whether accurately calculate the frictional resistance coefficient will directly lead to the accuracy of the pressure drop calculation. According to the oil and gas gathering and transferring design specification (GB 50350-2005), the frictional resistance along the pipeline can be calculated by Darcy formula, but the calculation formula is just suitable for non Newtonian fluid.

$$
h=\lambda \frac{L}{d} \frac{v^{2}}{2 g}
$$

\section{CI-CO:}

$h$-the friction along pipeline, liquid column, m;

$L$ - pipe length, m;

$D$ - pipe diameter, $\mathrm{m}$;

$v$-liquid flow rate, $\mathrm{m} / \mathrm{s}$, Which is the volume of crude oil flow,m $3 / \mathrm{s}$;

$g$-acceleration of gravity, $g=9.81 \mathrm{~m} / \mathrm{s} 2$;

$\lambda$-hydraulic resistance coefficient, determined according to table

TABLE I. CALCULATING FORMULA FOR HYDRAULIC RESISTANCE COEFFICIENT $\lambda$

\begin{tabular}{|c|c|c|c|}
\hline \multicolumn{2}{|c|}{ flow regime } & scope of application & calculating formula \\
\hline \multicolumn{2}{|c|}{ laminar flow } & $\operatorname{Re}<2000$ & $\lambda=\frac{64}{\operatorname{Re}}$ \\
\hline \multirow{4}{*}{$\begin{array}{c}\text { Turbul } \\
\text { ent } \\
\text { flow }\end{array}$} & $\begin{array}{c}\text { the } \\
\text { hydraulic } \\
\text { smooth } \\
\text { area }\end{array}$ & $\begin{array}{c}3000<\operatorname{Re}<\mathrm{Re}_{1} \\
\operatorname{Re}_{1}=\frac{59.7}{\varepsilon^{8 / 7}}\end{array}$ & $\begin{array}{c}\frac{1}{\sqrt{\lambda}}=1.81 \lg \operatorname{Re}-1.53 \\
\operatorname{Re}<10^{5}, \lambda=\frac{0.3164}{\operatorname{Re}^{0.25}}\end{array}$ \\
\cline { 2 - 5 } & $\begin{array}{c}\text { mixed } \\
\text { friction } \\
\text { area }\end{array}$ & $\operatorname{Re}_{2}=\frac{665-765 \lg \varepsilon}{\varepsilon}$ & $\frac{1}{\sqrt{\lambda}}=-2 \lg \left(\frac{\varepsilon}{7.4}+\frac{2.51}{\operatorname{Re} \sqrt{\lambda}}\right)$ \\
\cline { 2 - 5 } & $\begin{array}{c}\text { drag } \\
\text { square } \\
\text { area }\end{array}$ & $\operatorname{Re}>\operatorname{Re}_{2}$ & $\lambda=\frac{1}{(1.74-2 \lg \varepsilon)^{2}}$ \\
\hline
\end{tabular}

When $2000<\operatorname{Re}<3000$,it is transition zone and can be calculated as turbulent flow hydraulic smooth area.

\section{CI-CO:}

$$
\varepsilon \text {-pipeline relative roughness, } \varepsilon=\frac{2 e}{d} ;
$$

in which e is absolute roughness of pipe wall, $\mathrm{m}$, is determined by pipe, pipe method, pigging measures, corrosion and scaling.

In this article, the gelled crude oil - gas - water multiphase flow is non-Newtonian fluid, and the Reynolds number is in a mixed friction area. Type (16) is Colebrook formula which is widely used in the calculation of multiphase flow frictional resistance. But on the right side 
of the equation implied frictional resistance, is quite complicated to calculate. So this formula is simplified by many scholars .Dou Yisong [16] using mathematical statistics and regression analysis method to simplify Colebrook formula is the most typical and the highest precision, simplify the results as follows:

$$
\frac{1}{\sqrt{\lambda}}=-2 \lg \left(\frac{\varepsilon}{7.78}+\frac{5.58}{\operatorname{Re}^{0.9}}\right)
$$

The friction drag coefficient $\lambda$ also can be determined by Isaev formula or Atlas Schur formula: Isaev formula

$\frac{1}{\sqrt{\lambda}}=-1.8 \lg \left[\frac{6.8}{\operatorname{Re}}+\left(\frac{\varepsilon}{7.4}\right)^{1.11}\right]$

Atlas Schur formula

$$
\lambda=0.11\left[\frac{e}{d}+\frac{68}{\operatorname{Re}}\right]^{0.25}
$$

\section{THE COMPARATIVE ANALYSIS OF THE MODEL CALCULATION VALUE AND MEASURED VALUES DURING GELLED CRUDE OIL HYDRAULIC SUSPENSION TRANSPORTATION}

The experiment test values are shown in Table 2 and the comparison of the pressure drop results calculated through three friction coefficient models. The test and calculated by Colebrook formula values are shown in Figure.1. The results show that the pressure drop calculated by Colebrook, Isaev and Atlas Schur formulas error exceed $71 \%$. So, although the above formula used above the freezing point of mixed oil and gas water hydraulic pressure drop is relatively accurate, but the calculation below the freezing point of crude oil of the gelled crude oil - gas - water mixture pressure drop, the error is bigger.

TABLE II. THE COMPARISON OF PRESSURE DROP BETWEEN THE MODEL CALCULATED AND VALUE MEASURED VALUES

\begin{tabular}{|c|c|c|c|c|c|}
\hline $\begin{array}{c}\text { mixed } \\
\text { flow } \\
\text { velocity }\end{array}$ & $\begin{array}{c}\text { the } \\
\text { measured } \\
\text { pressure } \\
\text { drop } \\
\text { values } \\
\mathrm{Pa} / \mathrm{m}\end{array}$ & $\begin{array}{c}\text { Baker } \\
\text { model }\end{array}$ & $\begin{array}{c}\text { Colebrook } \\
\text { formula }\end{array}$ & $\begin{array}{c}\text { Isaev } \\
\text { formula }\end{array}$ & $\begin{array}{c}\text { Atlas } \\
\text { Schur } \\
\text { formula }\end{array}$ \\
\hline 0.47 & 391 & 239 & 69 & 68 & 67 \\
\hline 0.51 & 458 & 252 & 81 & 80 & 79 \\
\hline 0.55 & 490 & 261 & 92 & 91 & 90 \\
\hline 0.64 & 555 & 280 & 121 & 120 & 119 \\
\hline 0.70 & 582 & 295 & 144 & 143 & 141 \\
\hline 0.77 & 612 & 309 & 174 & 173 & 171 \\
\hline
\end{tabular}

\section{CONCLUSIONS}

Due to the temperature of oil-gas-water mixture is far less than the solidification point of crude oil, viscosity is high and friction loss is large and characteristics are complicated. So the method above isn't suitable for calculation of gelled crude oil's hydraulic transportation.
For this reason, new calculation method is needed to explore.

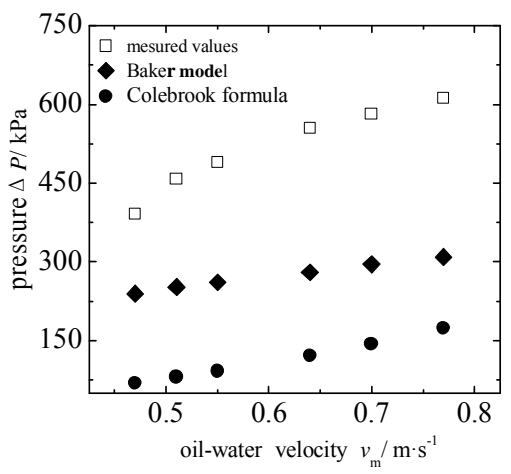

Figure 1. The comparison of pressure drop between the model calculated and value measured values

\section{ACKNOWLEDGMENT}

Thanks to the support of National Nature Science Fund (No.51176024), the natural science foundation of Heilongjiang Province(No.E201253) and the Education on Department of Heilongjiang Province (1254lz002). At the same time, thanks to the editors' and reviewers' important guidance and help for me.

\section{REFERENCES}

[1] Liu Xiaoyan, Zhang Yan, Zhao Bo. Pressure Drop Test in Oil Transportation Pipeline with Supper High-water-cut[J]. Oil and Gas Field Engineering,2005,24(12):7

[2] Liu Xiaoyan, Wang Dexi, Han Guoyou. Study on Temperature Limit during Oil Safe Production and Transportation with Supper High-water-cut [J]. Journal of Oil,2005,26(3):102-105

[3] Liu Xiaoyan, Liu Lijun, Guo Jinghong. Study on Pressure Drop Oil-gas-water Slug Flow in Horizontal Pipeline with Supper Highwater-cut [J]. Thermal Science \& Technology,2005,4(4):352-355

[4] Liu Xiaoyan, Zhang Yan, Liu Lijun. Pressure Drop Calculation Mathematics Oil-gas-water Slug Flow in Pipeline with Supper High-water-cut $[\mathrm{J}]$. Journal of Engineering Thermal Physics,2006,27(4):615-618

[5] Liu Xiaoyan, Zhao Bo, Zhang Yan. Pressure Drop Calculation Mathematics Oil-gas-water Slug Flow in Horizontal Pipeline with Supper High-water-cut[J]. IASME TRASCTIONS, 2005, 2(9):1648-1655

[6] Han Guoyou, Zhang Yan, Liu Xiaoyan. The Pressure Drop Calculation Method in Oil-gas-water Horizontal Pipeline with Highly-water[C]. Proceeding of the 3rd IASME/WSEAS Int. Conf. On HEAT TRANSFER, THERMAL ENGINEERING AND ENVIRONMENT, Corfu, Greece, August 20-22, 2005, 61-66

[7] Huang Binghua. Pressure Drop Calculation of Oil-gas-water in Transportation Pipeline[J].Oil and Gas Storage and Transportation,1996,15(5):8-12

[8] Chen Jie, Yu Da,Yan Dafan. The Experimental Research on Pressure Drop with Oil-water Flow in Horizontal Pipeline[J]. Experimental Mechanics,2001,16(4):402-408

[9] Gong Jing, Mu Hong. Research on High Viscous Oil-water Flow Pressure Drop in Horizontal Pipeline [J]. Oil and Gas Storage and Transportation, 2004,23(6):38-41

[10] Liu Wenhong, Guo Liejin, Zhang Ximin. Pressure Drop of Oil-gas Flow in Straight Horizontal Circular tube[J]. Journal of Chemical Industry, 2004,55(6):907-912 
[11] Hall A RW et al. An Experimental Investigation of the Water Phase in the Multiphase flow of Oil, Water and Gas, Proc. 6th Int. Conf. on Mutilphase Production, France, 1993

[12] Neogi, Lee and Jepson. A Model for Multiphase (Gas-Water-Oil) Stratified Flow in Horizontal Pipelines. Society of Petroleum Engineering of Aime, 1994

[13] Odozi U A, Mendes-Tatsis M A, Hewitt G F. Three Phase AirWater-Oil Flow Patterns, ASME 1998, Proceeding of the ASME Heat Transfer Division, 1998
[14] D. P. Chakrabarti, G. Das, and S. Ray. Pressure Drop in LiquidLiquid Two Phase Horizontal Flow: Experiment and Prediction[J]. Chemical Engineering \& Technology, 2005, 28(9): 1003-1009

[15] Liu Xiaoyan, Fan Wei, Wang Zhonghua, Wu Chuanyan, Li Fuzhang. Study on Pressure Drop Characteristics of Water - gel Crude Oil Flow [J]. Journal of Engineering Thermal Physics, 2014,35 (4) :695-699

[16] Dou Yisong, He Xijie. Calculation Method of Pipe Friction Resistance Coefficient [J]. Journal of Hydraulic, 1995,7,22, 28-31 